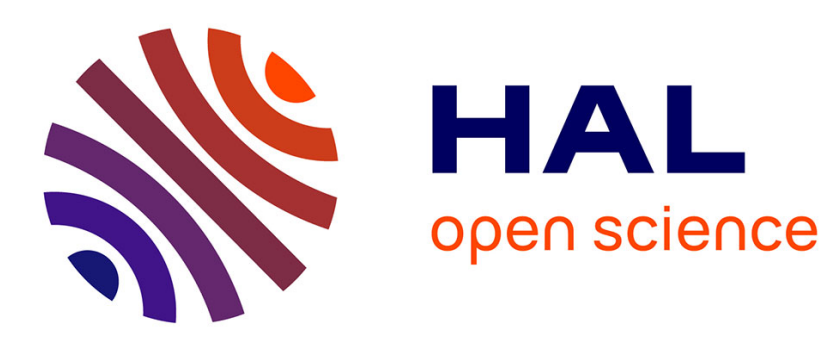

\title{
Systems approach to modelling cost and value dynamics in Manufacturing Enterprises
}

\author{
Kwabena Agyapong-Kodua, R H Weston
}

\section{To cite this version:}

Kwabena Agyapong-Kodua, R H Weston. Systems approach to modelling cost and value dynamics in Manufacturing Enterprises. International Journal of Production Research, 2010, pp.1. 10.1080/00207540903436661 . hal-00592059

\section{HAL Id: hal-00592059 \\ https://hal.science/hal-00592059}

Submitted on 11 May 2011

HAL is a multi-disciplinary open access archive for the deposit and dissemination of scientific research documents, whether they are published or not. The documents may come from teaching and research institutions in France or abroad, or from public or private research centers.
L'archive ouverte pluridisciplinaire HAL, est destinée au dépôt et à la diffusion de documents scientifiques de niveau recherche, publiés ou non, émanant des établissements d'enseignement et de recherche français ou étrangers, des laboratoires publics ou privés. 


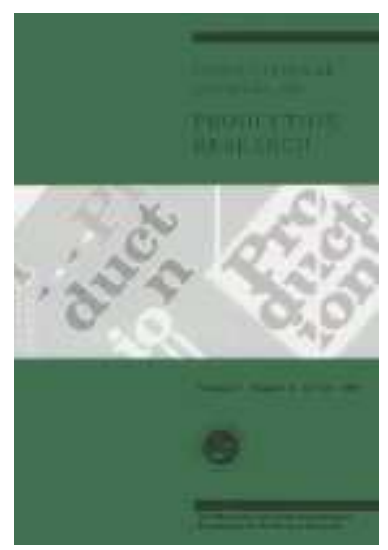

\section{Systems approach to modelling cost and value dynamics in Manufacturing Enterprises}

\begin{tabular}{|r|l|}
\hline Journal: & International Journal of Production Research \\
\hline Manuscript ID: & TPRS-2008-IJPR-0108.R1 \\
\hline Manuscript Type: & Original Manuscript \\
\hline $\begin{array}{r}\text { Date Submitted by the } \\
\text { Author: }\end{array}$ & 07-Oct-2009 \\
\hline Keywords: & $\begin{array}{l}\text { MANUFA of Authors: } \\
\text { Coston, R H; Loughborough University, Wolfson School of Mech } \\
\text { and Man Engineering }\end{array}$ \\
\hline Keywords (user): & COST \& VALUE DYNAMICS, CAUSAL LOOP MODELLING \\
\hline
\end{tabular}

\section{S ScholaroNE \\ Manuscript Central}




\author{
Systems approach to modelling cost and value dynamics in Manufacturing \\ Enterprises \\ K. Agyapong-Kodua and R H Weston \\ (k.a.kodua@lboro.ac.uk,r.h.weston@lboro.ac.uk*) \\ MSI Research Institute, Loughborough University, Loughborough, Leics., UK; Tel: 01509227501
}

\begin{abstract}
Operations and activities in Manufacturing Enterprises (MEs) are undergoing frequent changes as a result of external and internal factors which actively impact on the structures, processes and work patterns of most MEs. These changes induce complexities and dynamics in the survival of most MEs. As a result of the changes, cost and value generation are also affected. To remain competitive, MEs have to continuously and flexibly adjust through the redesign and organization of their processes and resource elements with the aim to improve key performance indicators including cost and values. This is however not simple to achieve because of the inherent and ongoing dynamics experienced by MEs.
\end{abstract}

This paper shows how system dynamics modelling techniques in the form of causal loop and iThink simulation, can be coherently used to capture salient factors which induce dynamics in MEs. The integrated modelling technique was further used to show how dynamic impacts of MEs on cost and value generation can be conveniently modelled and analysed to support decision making related to competitiveness and profitability of a case study furniture manufacturing company.

Key words: Manufacturing Enterprise (ME), cost and value dynamics, Causal Loop Modelling (CLM), Simulation Modelling (SM)

\title{
1.0 Introduction
}

Conventional means of generating and developing Manufacturing Enterprises (MEs) involves bringing people together and providing them with structure and technology for doing work (Davis 1982). In most MEs various inputs flow through networks of resourced activities to enable outputs of various forms to be achieved (AgyapongKodua, Bilal et al. 2007). This means that proper organization of resource elements and business processes in support of enterprise requirements and deliverability is necessary for the survival of the ME. It is therefore required that business processes and their associated resource elements are designed and organized such that value is added to inputs (raw materials) along well defined process threads to obtain outputs (finished

\footnotetext{
${ }^{*}$ Corresponding author
} 
products) meeting customer requirements. In the process of deriving this objective, cost is incurred through the distributed use of resources and materials. Best industrial practices recommend that competitive business processes should have less cost consumption and high value generation (Agyapong-Kodua 2009). Also it is necessary that values so attained are translated into equivalent monetary 'regard' in the form of prices customers are willing to pay. How this can be achieved efficiently will help MEs to develop internal structures and manufacturing policies which reflect customer's perspective of value.

Typically, lots of factors influence the cost of production in MEs. The recent challenges of globalization; varying customer requirements; the drive towards mass customisation; changes in machine and computer technologies, environmental and social constraints have compounded and complicated the issue of timely product and process costing. As would be expected, these external factors impact on the internal operations of MEs and it is necessary to re-organize the internal structures and processes to annex the impact of their effects. The reason is that most MEs are composed of complex process networks which are inter related in a way that changes made to one process thread induce dynamics in the ME by having causal and temporal effects on other process threads . These dynamics play key roles in 'cost consumption' and 'value generation'. Cost and value are key performance indicators for any ME operating in a dynamic market environment. This is due to their ability to ensure competitiveness of the enterprise. It is therefore useful to adopt methods capable of modelling aspects of dynamics that impact on cost and values. When this is achieved scientifically, measures can be taken to improve value generation along process segments.

Literature has shown that in broad terms, current best modelling techniques with potential to define, measure and utilize aspects of value and cost information in manufacturing processes can be classified into:

1. Process Mapping techniques (PMs) (Bicheno 2000; Womack and Jones 2003)

2. Enterprise Modelling (EM) techniques (Vernadat 1996; CEN/ISO 19440).

3. Cost Modelling techniques (Humphreys 1987; Akintoye and Fitzgerald 2000)

4. System Dynamics (SD) Modelling techniques (Forrester 1961; Sterman 2000) 
5. Business Process Simulation Modelling (SM) techniques (Carrie 1988; Kosanke 1996)

PMs (for example: value stream mapping, process activity mapping, overall lead time mapping and product variety funnel) are not suitable for capturing aspects of complexities and dynamics in MEs (Scholz-Reiter, Freitag et al. 2004; AgyapongKodua 2009). This is because most of the PM tools were designed for mapping processes of linear orientation and do not reflect real-time dynamic instances of MEs. It has also been reported that PM tools do not possess the ability to reflect causal impacts of activities on processes (Agyapong-Kodua, Bilal et al. 2007). Enterprise Modelling (EM) tools (for example: CIMOSA, ARIS, PERA) relative to PM tools offer additional modelling concepts that enable the capture of semantically rich models of various aspects of enterprises (Weston 1999; Vernadat 2002; Ajaefobi 2004). The models provide a multi perspective view of enterprises and thus is more suitable for analysing complex aspects of businesses. In theory enterprise modelling approaches facilitate the design and development of better processes and systems, and can improve the timeliness and cost effectiveness of change projects in MEs, but full and industry wide benefit in practice is yet to be realised (Bernus and Nemes 1996; Vernadat 1996; Agyapong-Kodua 2009). EM tools generate models which are static and demand appropriate transformation mechanisms into 'real-time' dynamic simulation models.

Business Process Simulation Modelling techniques (SMs) generate useful dynamic representations of discrete processes in MEs. They are therefore suitable for 'what-if' analysis of business processes and supports virtual process design technologies. However, SMs do not suitably model 'cause and effect' structures of processes and are therefore not suitable for detailed 'process dynamics and complexities' modelling. Cost modelling techniques on the other hand provide a framework for estimating cost based on mathematical algorithms derived from observations and analysis of historic data. They can provide support to any of the modelling techniques explained above in estimating process or product cost. 
Literature however shows that SD techniques offer a unique approach towards the modelling of complexities and dynamics in systems (Richardson 1999; Wolstenholme 1999; Sterman 2000). SD models are able to capture factors or elements which induce dynamics in many social, health, political and economic systems (Burns and Ulgen 2002). Later attempts have been made to use these techniques in support of the design of manufacturing systems (Ajaefobi 2004; Chatha 2004,). Little successes have been reported though and this may be due to the inability of these techniques to critically model processes at the elementary level. In essence, they are useful tools for capturing and analysing factors which impact on processes and their executing agents.

To further support the application of SD techniques in manufacturing environments, the authors have illustrated how SD techniques can be deployed to model aspects of dynamic instances related to cost and value creation in a make-to-order manufacturing enterprise. Causal Loop (Forrester 1971; Sterman 1984; Burns 2001) and iThink/Stella (ISEE 2007) modelling techniques were considered very useful in this application. They were coherently used to model aspects of dynamics in MEs which impact on cost and values. The output resulted in generic (or semi-generic) models which are capable of providing support in the analyses of the impact of dynamics on cost and values.

\subsection{Dynamics in Manufacturing Enterprises}

The domain of 'dynamics' is traditionally associated with machines and control systems (Forrester 1961). However literature shows that in general terms, the problems often faced by most manufacturing enterprises can be rooted to the phenomenon of complexity which stems from the complexities involved in current markets (Wiendahl and Scheffczyk 1999). The structural and dynamic complexity of the markets can be found in the structure and processes of the enterprise too. Hence the complexity of the products have their counterparts in the complexity of the manufacturing systems. For most MEs the dynamics of complexities can be enormous. Partly because MEs are highly organic (people-centred) and achieve their goals only through the integration of people, machines and technology. As a result of the interaction between these functional elements, changes related to any of the elements trigger effects on other elements which are causally related to other elements hence producing 'chains of reactions' in MEs. It is 
therefore required that decisions associated with processes and their related resources be made properly so that they can best be coordinated to achieve optimal results.

To achieve this, most MEs in their life time would have to realise networks of processes comprising the following process types (Weston 1999): (1) processes that realise products and services for customers and values for stakeholders; (2) processes that ensure that product and service realisation is well managed, such that it remains aligned to established business and manufacturing policies, and strategic goals of the ME, and 3) processes that structure and enable ongoing change as the ME systematically renews and reconfigures itself, developing and implementing new strategies, policies and processes in response to external change. The realisation of these sets of processes are often inhibited by the external factors described in the previous section. In addition, internal issues like machine breakdowns, resource unavailability, shortage of material, operational delays and improper product and resource routings, among other disturbances, also affect MEs. The net effect of the impact of these external and internal factors result in the dynamics or complexities which are imposed on the ME.

\subsection{Impact of ME dynamics on cost and value generation}

The management of the impact of dynamics on cost and value generation is of prime importance if any business is to survive in a competitive and complex market environment. This is so because cost and values are part of the key performance indicators needed in the determination of efficiency and profitability of every business. This is the reason why this paper has focussed on modelling aspects of manufacturing dynamics which impact on cost and values.

Cost is considered to be related to the total cost of resources, materials and their associated support systems which span across the entire supply chain. On the other hand, product value in real economic sense is dependent on market forces. Essentially it is the worth or price that customers are prepared to pay. Most critically, it is dependent on how customers assume the value of the product relative to its ability to solve their needs taking into consideration the product's competitiveness in terms of prices of substitute products (Agyapong-Kodua 2009). 
It is viewed that cost and values can conveniently be defined in the form of a network of distributed factors from business process models. In effect if a change necessitates the utilization of more resources without an appropriate increase in value then it means that the business will have to cope with running at higher cost of production. On the other hand, if higher values can be attained without necessarily increasing the cost then the business will become competitive on price and may win larger market shares. Latter sections have identified how dynamic models of cost and values can help solve the problems of dynamics and complexities associated with cost reduction and value creation. This involves modelling the set of particular or generic factors which impact on resources, processes, and materials. Resolving cost and value dynamics from this perspective helps eliminates distortions associated with conventional cost allocation methods (Johnson and Kaplan 1987). In this approach, instead of allocating cost and assuming values, a description is made of the factors which induce dynamics along process segments such that changes in these factors can be visualised. This gives instantaneous reflection of the impact of changes on the production system.

\subsection{Review of system dynamics modelling tools}

The overwhelming dynamics in MEs require that techniques which enable effective scientific reasoning about complexities and causes of dynamics in MEs be deployed. Modelling and controlling complexities with conventional methods is becoming more difficult (Goldhar and Jelinek 1983) especially with advancing technologies and varying customer requirements.

Generally to aid the analysis of complexities and hence manage dynamics of manufacturing enterprises, modelling plays a key role. Modelling is often used to derive an electronic replication of real life systems so that analysis can be conducted on the system without having to interfere with the operation of the real life systems (Carrie 1988). Several literature have enumerated the benefits of modelling in manufacturing systems (Askin 1993; Vernadat 1996; Rolstadås 2000; Rahimifard and Weston 2007). It is behind this background that system dynamics modelling techniques are used to illustrate how dynamics and systems complexities can be fairly modelled to aid decision making and experimentation in MEs. 
Some scientific methods which have won popularity in terms of their wide usage in modelling dynamics and complexities in systems include Fuzzy Logics (FLs) (Batur, Srinivasan et al. 1991; Wang 1992; Yester, Sun et al. 1993), Neural Networks (NNs) (Minsky and Papert 1969; Gardner and Derrida 1988; Spooner, Maggiore et al. 2002), Bayesian Networks (BNs) (Pearl 1985), Petri Nets (PNs) (Peterson 1981; Zhou and Venkatesh 1999), Causal Loops (CLs) (Forrester 1961; Burns and Ulgen 2002) and Stock and Flow models (Randers 1980; Sterman 2000; Binder, Vox et al. 2004). Table 1 shows the relative strengths of these complex system modelling tools.

The strong mathematical base of system dynamics modelling tools discourage lots of manufacturing experts from deploying them (Agyapong-Kodua 2009). This is particularly so in the case of BNs, FL, NNs and PN technologies.

The CL technique however does not involve complex mathematical expressions and it is good in illustrating, qualitatively, the cause and effects evident in a system. Also reported is that the CL modelling technique could be used together with process modelling techniques to capture and analyse the causal impact of activities on various business performance indicators. Thus CLs lend support for complex manufacturing systems design. Also factors which influence value generation and cost can be captured and expressed on process-based models for effective economic analysis of manufacturing processes.

For simplicity and first stage qualitative analysis, CLs are considered to be most suitable. However CL models cannot be simulated in their natural state and needs to be enhanced to equivalent simulation models before in-depth process and business analysis can be performed. Generating simulation models can help save cost, generate best results, promote enterprise integration, improve value generation and support the derivation of methods for improving processes in MEs.

\section{Insert Table 1}

\section{Table 1: Review of system dynamics modelling tools}


Many commercial simulation software exist but the iThink continous simulation tool best support CL models (ISEE 2007). More so causal relationships can best be described in iThink since it is basically an extension of CLs (Agyapong-Kodua 2009). In general terms iThink is good at depicting overall business behaviour (Sterman 2000).

\subsection{Causal loop (CL) and related stock and flow (SF) modelling approach}

CLs and SFs evolved from research in control engineering and non-linear dynamics theories (Forrester 1961; Coyle 1983). Literature shows that CL and SFs have been successfully applied in public policy making and implementation (Morecort and Sterman 1994; Richardson 1996); product development and project management (Ford and Sterman 1998); depicting the dynamics of infectious diseases like HIV (Mosekilde 1996; Sterman 2000); transportation policy and traffic congestion analysis (Meadows 1974; Sterman 2000); supply chain management (Akkermans 1995) and also as an integrated simulation tool (Wolstenholme 1999; Homer and Oliva 2001; Chatha, Weston et al. 2003). Arguably, the best known application of system dynamics is the world model of Forrester and Meadows (Forrester 1971; Meadows, Meadows et al. 1971), although it has extensively been criticized by Burke as gross underestimation of corrective mechanisms in the world demographic economic system (Burke 1973). Many examples of the application of CLs and SFs appear in publications by Sterman (Sterman 2000), Forrester (Forrester 1980; Forrester 1992), Burns (Burns and Ulgen 2002), Wolstenholme (Wolstenholme 1990; Wolstenholme 1999), Richardson (Richardson 1999) and Meadows (Meadows 1974; Meadows and Robinson 1985).

CL modelling has long been used in standard system dynamics practice for purposes connected to simulation modelling (Binder, Vox et al. 2004). Basically, it contains variables, and arrows which show the causal relationships between the variables. Increasingly, they are now being used to depict the basic causal mechanisms hypothesized to underlie reference mode of behaviour over time, that is for articulation of a dynamic hypothesis of the systems as endogenous consequences of the feed back structure (Randers 1980; Richardson 1999). 
CLs are known to be useful for:

- depicting relationships between cause and possible effects (Homer and Oliva 2001; Binder, Vox et al. 2004)

- creating dynamic models of businesses for alternative policy verification (Wolstenholme 1999; Homer and Oliva 2001)

- capturing mental models of individuals and teams during start of projects and also during project dissemination (Ford and Sterman 1998)

- demonstrating the transformation from static modelling to dynamic modelling (Chatha, Weston et al. 2003; Weston 2005).

Causal loop modelling starts with a variable followed by an arrow which shows the causal links with the effect associated with the variable. Each causal link is denoted by a positive or negative polarity to represent how the variables change in respect to the other. A loop is called positive, regenerating or reinforcing if it has no negative polarized links or if the sum of the negative links is even. Otherwise it is a negative or balancing loop.

In most (if not all) MEs and public policy analysis, it is necessary to quantify the effect of actions before they are taken because of the cost implications they often possess. But as would be observed in the case study applications, the causal loop modelling technique is suitable for qualitative analysis and decision making related to cause and effects. To help quantify alternative business policies, quantifiable 'stock and flow' models are often deployed by researchers in the area of systems thinking. In this paper, an enhanced form of 'stock and flow' model in the form of iThink simulation model is presented.

Proponents of causal loop models laude their accessibility to no-experts and claim that simulation models in the form of 'stock and flows' are useful only for people who understand them (Ford and Sterman 1998). Although this may be true, Weston (Weston 1999) noted that 'when the end goal of a modelling exercise is to quantify benefits that can arise from manageable decisions then there arise a need to create models that replicate process behaviours in the context of their use'. They further explained that 
verified models can be used to predict better ways of optimizing the performance of organizations. In effect the application of dynamic simulation models in manufacturing enterprises can help solve problems of parameter optimization; design of control policies; system operation checking; performance evaluation; system dimensioning and the test of design alternatives (Vernadat 1996).

\subsection{System dynamics model of case company}

\subsection{Description of case study company}

The case study is about a 'make-to-order' furniture company located in the East Midlands of the United Kingdom. The company operates with about fifty regular employees and uses basic furniture manufacturing equipment like sanders, grinders, polishes, benches, saws, planers, etc. Figure 1 shows an overview of the operations of the company. Orders received are grouped and transformed into 'production runs'. These runs are based on the capacity of the fleet of transport vehicles owned by the company and logistical criteria related to the geographical location of customer stockists.

\section{Insert figure 1}

Figure 1: overview of operations in the case study company

These runs are converted to a 'so called' picking list which lists the furniture items that need to be manufactured and dispatched to the assembly section. The assembly shop supervisor then issues a mini-order to the machine shop on parts which need to be machined. The machine shop however usually envisages demands at the assembly shop (based on experience) and therefore produces stockpiles of parts which are loaded on racks located in the assembly shop. Parts assembled are transferred to the spray shop. Finishing operations are performed on these sub-assembled parts as they are released from the spray shop, before final delivery. The total production lead time is approximately 4 weeks. This lead time changed significantly to eight weeks when there was an unexpected increase in customer demand. This was partially due to the company's inability to increase their 'effective' manufacturing capacity to match the customer demands. 


\subsection{Development of causal loop models of case study company}

To generate a well informed system dynamics model, it was necessary to review documentation related to operations, production and sale of the products. Most importantly, data related to cost and value generation were reviewed whilst typical operational processes were observed by the authors at the shop floor of the case company. The various shops were required to work with various mixes of products at varying times and quantities to meet the customer requirements. Thus resources were shared and distributed in patterns which in reality caused backlogs at some work centres. This necessitated the need for capturing the shop floor operations and creating models to help improve performance. With the interest of investigating the effect of changes on cost and value, an initial semi-generic causal loop model was created to help provide useful insight about the changes and factors which impact on cost and value. Fundamentally, for the case company to remain competitive, it must produce products which cost less, with enhanced values and more flexible to changes in production and market conditions. With this background and from a general perspective, it was noted that the rate of delivery of finished goods to customers was partly dependent on the production rate achieved. However the required delivery rate was dependent on the market demand and customer requirements which in a way was expressed in the form of customer orders recieved by the company. Also the production rate achieved was dependent on a number of factors which included the production capacity, ordering rate and the rate of raw material supply. These factors have been illustrated in the open causal loop model shown in figure 2

\section{Insert figure 2}

\section{Figure 2: open causal loop illustrating factors affecting production rate achieved}

To achieve the research aim, in-depth understanding about the case company process dynamics was required. This was achieved by investigating further the exogenous factors which influenced the factors shown in the model (see figure 2). The investigation was done by interviewing the Sales and Production Managers of the case company. 
In considering the production rate required, it was observed that factors such as units of work required per item input, product lead time based on customer ordering requirement, estimated work rate of resource elements, expected material supply or availability and internal company manufacturing policies, among others, were necessary. On the other hand, the actual production rate the company achieved was dependent on actual competence and availability of resources and raw materials, ordering requirements, storage and delivery implications. In reality efforts are always made to minimize the difference between the two production rates. The factors described above and other factors which impact on the production rates have been described in figures 3(a) and 3(b). Figure 3(a) shows the initial model which was captured to help understand the factors influencing the production system. Although the final measures were in 'rates', the variables were not captured in time-dependent frames hence the term 'rate' was not used to define them initially.

\section{Insert figure 3(a)}

Figure 3(a): An initial causal loop model describing the impact of production activities

In a more refined or structured model (figure $3 b$ ) the various time dependent factors were modelled in their lowest form.

\section{Insert figure 3(b)}

\section{Figure 3b: Initial structured causal loop model}

It was also observed that the production rate achieved impacted positively on the rate of value generation and hence the rate of profit realisation by the company. The cost consumption rate was also influenced by the cost per unit of resource utilization and the sum of all other businesses and material costs.

These two initial models were presented to the Production Manager of the case company to verify if they best represent the factors which normally affect their operations. The feedback obtained from the Manager indicated that the factors and links described in the models were correct. The Manager confirmed that, in general terms, the initial causal loop models enhanced his understanding about how factors were interrelated and therefore the need for an integrated solution approach. 
After the initial models were verified, a decision was taken to create specific causal loop models which illustrate the reinforcing and balancing loops that existed in the company's operations. As a result, the Sales Manager was interviewed to establish how sale orders were generated. Previous work orders were also studied to establish how many sale orders were produced in time. This was to help establish the impact of increased sale orders on current production capacity. Through the interaction with the Sales Manager, it became evident that the major source of boosting their sales was through sales team promotions and advertisement. Historically, increase in number of sales promotions and adverts, increased the number of orders the company received. This was demonstrated in the number of emails and faxes as well as telephone orders the company received. Although obvious, the Production Manager confirmed that the increase in sale orders increased the work load on the production system. The work load was in the form of orders to be processed, production runs to be generated and the organization of resources to meet the new order requirements. One of the facets of the work load is described in the loop as having a positive influence on the resource utilization. These resources were in the form of machines, humans and technology required to meet the customer needs. The effect of human resource utilization has been depicted in the main regenerative loop, R1. In the case company, increase in resource utilization coherently increased the labour force required. This reflected in the form of the number of casual or agency staff the company had to employ to meet their required capacity.

\section{Insert figure 4}

Figure 4: Balancing loops showing effect of increase in customer orders

The major strategy adopted by the company in seasons of high work loads is to hire workers which tend to temporarily increase their labour force. Historically, the increase in their labour force increase the total number of finished goods. This promoted the timely supply of goods to the customers since delivery schedules were closely tied to completion of the production schedules. This timely supply of finished goods was necessary for customers to maintain their trust in the company. 
It was however observed from the company data that as demand increased, the lead time changed from four weeks to eight weeks. The subsequent balancing loops, B1 and B2, shown in figure 4 have depicted why there were such delays. From B1 it is clear that the increase in customer orders necessitate an increase in raw materials. This relationship is critical because the case company operated a low stocking policy which allowed only minimal stock of parts to be kept Since the company does not produce its own raw materials, it had to rely on their external suppliers in the mainland United Kingdom and the Scandinavia for supply of raw materials. Hence delays in supplies destabilised production. This delay had direct effect on production lead time and was one of the major causes of the long lead times experienced.

By studying B2, it is evident that customer orders are transformed into mini orders to the assembly and machine shops. The mini orders which go to the machine shop are to alert the machine shop operators of parts which would be required for assembly. Most often the machine shop operators anticipate stock requirement, based on experience, and machine parts to stock. This was based on existing general demand forecast. The unexpected increase therefore increased the number of operations in the machine shop as well as the net utilization of the machine shop. Apparently the total orders were greater than what the capacity of the machine shop could cater hence production backlog was created. The reason was that since the operations of the machine shop was machine-intensive, the increase in work force did not necessarily impact on the timely production of parts. The backlog created had a consequential delay on assembly operations. For instance the assembly of some tables had to be suspended for six days until table tops were machined at the machine shop. A delay in assembly operations affected the total number of finished products and hence the net orders received over the time period.

Other positive and negative loops describing the impact of their activities on cost is shown in figure 5. As can be observed from the loops shown in figure 5, B3 shows that the increase in labour force impact positively on labour cost. Labour cost is an essential and incremental aspect of production cost, therefore the increase in labour cost cause an 
increase in the cost of production. Without the association of the appropriate level of value creation in favour of customer demand, the increase in production cost has a negative impact on profit margin as well as the total revenue to generated.

As a business strategy, part of revenue generated is invested in sales promotional activities, which has proven to increase customer awareness and hence company's competitiveness.

\section{Insert figure 5}

Figure 5: Loops describing impact of activities on cost

R2 shows that with increasing competitiveness, large market shares are obtain hence providing a strong customer base capable of generating high profit margins.

Other positive loops of interest are shown as R3, R4 and R5. They illustrate the impact of increase in resource utilization on training and tool cost. In R3, it was observed that increase in resource utilization caused the company to employ more temporary workers who were trained to take up available jobs. Some cost were incurred in the form of training materials, training personnel and resource utilization time. Another prime regenerating loop demonstrating how the cost of tooling was increased in the long term is shown by R4 and R5. R4 demonstrates that as the number of staff increased there was corresponding increase in the number of tools required for the job. Tools in this sense refers to bench working tools like chisel, hammer, drills, polishers, etc which are often contained in a tool box. The purchase of these tools increased the total cost of tools acquired by the company. Also R5 shows that the increase in the number of workers increased the rate of tool usage which resulted in a high rate of tool wear, thereby increasing the total tool cost.

Figure 6 shows the overall influence diagram representing a collection of the causal loop models already explained in preceding pages.

\section{Insert figure 6}

Figure 6: Influence loop 1 of case study company 


\subsection{Stock and flow models (iThink simulation model) for analysing cost and value dynamics}

Previous sections have explored various forms of the causal loop models with the view of depicting the causal relationships between some salient factors and cost and values. This was good to illustrate the feed backs associated with decisions and operations in the company. Discussing these outcomes with Managers of the Company, they expressed satisfaction in the level of learning the models gave them about their own operations. Most importantly, they understood that causal impact of one activity on the other. Without providing quantitative evident of the extent causal variable influenced each other, the Managers confirmed that the models themselves were adequate to qualitatively explain the influential factors on cost and values hence suggesting which 'levers could be pulled to enact required behavioural pattern of cost and values'. This was necessary since it depicted the consequential effect of actions and activities on the shop floor. Not withstanding the causal loop models could not capture the stock and flow structure of the company for quantification purposes. This is required because 'stock and flow models' put structures around causal loop models to avoid misunderstanding and misinterpretation (Sterman 2000).

The conversion of structured causal loop models into 'stock and flow' models require further understanding of the variables in the model and their associated links. The first step in the conversion process is to identify the stocks in the model. Stocks are identified by studying the CL models to observe which of the factors possess a sense of accumulation. This is confirmed by noting the links which flow into those variables. Further verifications can be made by identifying the units of measure. Once stocks are identified, all other factors are either flows or converters. The difference is depicted through the nature of the outgoing dependencies. The only means a stock could change is through the influence of a flow. Hence a measure of the flow is the unit of the stock per unit time. Besides stocks and flows, other variables influence systems. These are termed converters. Converters hold values for constants, defines external inputs to the model, calculates algebraic relationships, and serves as the repository for graphical functions. They are linked to the model through connectors. A description of these modelling elements is shown in figure 7. Input converters are defined as all factors 
which are affected by nothing (no other factors) whilst output converters are factors which do not affect anything.

\section{Insert figure 7}

\section{Figure 7: Elements of stock and flow models}

A snapshot of the iThink system dynamics simulation model derived from figures $3 \mathrm{a}$, $3 \mathrm{~b}$ and 6 , taking into consideration the definition for stocks, flows and converters given above is shown in figure 8 . With the adoption of the software, there was no need of going through the rigorous mathematical transformations proposed by some literature.

\section{Insert figure 8}

\section{Figure 8: Portion of iThink system dynamics model}

\subsubsection{Simulation results and analysis}

To help validate the model, initial data was inputted into the model and the results were compared with observed trends of performance in the company. Factors such as actual production rate, product value, profit generated, material supply volume, customer orders, labour cost and material cost were critical variables which were verified by the Production Manager to confirm that the model best described their production system. The logic behind the connectors were also verified and identified to best represent the process states. The existing orders received from customers were mapped against the total cost consumed during the production process and the value generated as well as the profit attained. The graph shown in figure 9 shows a typical model output given a set of constant orders to be processed by the company. This graph was generated through the simulation software based on a set of well defined mathematical relationships between the parameters. Details of the graph has been given in Table 2, which is also an option provided by the software. From the graph and table (figure 9 and Table 2) shown, it can be deduced that for a fixed order of 20 , the profit, which is a representation of the difference between the total cost and value generated was marginal. This was within the region of $£ 3238$ and $£ 4238$. the difference was as a result of the difference in the product types which the customers ordered. 


\title{
Insert figure 9
}

\section{Figure 9: sample iThink system dynamics results}

\section{Insert Table 2}

\section{Table 2: sample simulation results}

\begin{abstract}
That is to say the company made more profit on some product classes than others. The simulation model therefore assisted in informing the company about their capital intensive products as well as their primary profit generating products. Although this was knowledge which existed in the finance department, the modelling results helped validated this assertion and also it became a relevant issue for the production department also. It was realised from the graph that after an initial stage, the product value kept increasing whilst the cost and orders remained approximately constant. The cost was approximately constant because after the initial capital intensive investment, the average cost spread over each month was marginal. Also since the number of human resource and machines remained the same the only variable was the material cost which also did not change significantly based on the order types received. Hence for a company operating within a relatively stable market conditions, values can be enhanced without necessarily increasing the cost. This knowledge was satisfying to the Managers of the company. Thus in reality the ability of a company to annex the effect of market instabilities contributes greatly to their value generation.
\end{abstract}

According to the Managers of the company, these initial results depicted their current business situation and hence was confident that the model was useful for conducting further experiments which could support decision making in the company. Hence series of experiments were conducted on the model to inform Management of the company about the implication of some business decisions. These experiments were constrained within the perimeters of the interest of the research so that well focussed results could be obtained. A key experiment was conducted for the sustainability of the company in varying customer order conditions. Figure 10 gives a snap shot of the graph representing the effect of customer order increase on the company. It can be deduced from the graph that as the customer orders increased there was increase in both the cost 
and value generated. The product value exceeded the cost, implying that the company was making profit until the fourth order when the cost exceeded the value generated. Thus after the fourth order, the company can not produce profitable products meeting customer specifications.

\section{Insert figure 10}

\section{Figure 10: Graph showing the effect of increase in orders}

It became clear that the fourth month with average order size of 40 was the maximum order size which the capacity of the company could sustain. This resulted in the heavy delays and queue sizes at the machine shop. The results further confirmed to the Managers the maximum orders the current production system is capable of maintaining.

With this limitation in mind the authors investigated the alternative deployment of extra machine resources. The focus was based on the machine resources because the shop where the delays occurred were machine intensive and the operations did not depend on the number of human resources available. It was purely based on the capacity of the machines. Hence the model was redefined to include an extra CNC machine. The results proved worthwhile and the system yielded higher values at less cost, rendering the company competitive and more profitable. A snap shot of the results is displayed in the graph shown in figure 11 . The graph shows that the initial introduction of the new equipment will not generate enough profit with low customer orders. That was to be expected as the existing capacity was suitable to satisfy low orders. The benefit was clear only at high customer orders. It also denotes that at low ordering capacities equipment may be idle. The decision to invest therefore lies on the company's desire for expansion or ability to win more customer orders.

\section{Insert figure 11}

\section{Figure 11: Graph showing the effect of introduction of new equipment}

Several experiments related to the effect of competition on the company, resource allocation, machine breakdowns, alternative manufacturing policies like pull and postponement were also investigated, with the base line understanding of evaluating the effect of these decisions on cost and values. The findings and interest of the results 
derived from those experiments fall outside the jurisdiction of this paper hence have been reported in other documents.

\subsection{Observations about system dynamics modelling of cost and value dynamics}

Throughout the research it was observed that the process of capturing elements impacting complexities and dynamics on cost and value generation demanded adequate data collection and thorough understanding of the processes being modelled. The close collaboration of the authors and the staff of the case company was necessary for the successful data collection, validation and analysis. In the case of the company under investigation, various causal loop models describing the operations and change enactors in the company were created. Specific portions of the causal loop were transformed into iThink simulation models for further analysis in terms of a) replicating and understanding historic enterprise behaviour and responses; b) predicting future enterprise behaviours and impact on performance indicators and c) experimenting alternative decisions before implementation to save cost and errors.

In carrying out this research the following observations were made:

1. The causal loop modelling technique was helpful in predicting the possible effects of potential change parameters in the company. Manufacturing elements which impacted on cost could fairly be modelled and controlled. The operation of the company was better understood in the process of modelling with the causal loop technique. The method was not very rigorous but fairly simple to understand. This is the reason why it can easily be misunderstood and interpreted wrongly. It was also observed that identifying key variables was not simple. It demanded thorough understanding of the business processes. A clear limitation of the causal loop modelling technique observed was that each of the loops could be further modelled in detail. The challenge involved is that the end model becomes complex and difficult to understand. As a result, the idea behind creating the model could be lost. The ability to determine the point to end 'decomposition' of variables becomes a key issue to the modeller. Extended literature on process decomposition can be found in (Vernadat 1996; Chatha and Weston 2005; Agyapong-Kodua 2009). Another observation was that until the 
models are clearly explained by the modeller it is quite difficult to comprehend as some variables and links could have multiple meanings. That is why for each of the models created attempt was given by the authors to provide explanation in words to outline the meanings of the cause, effects and links involved in the model. Although links and possible effects of causes were observed it was not possible to know the extend of the change which was happening in the company. This gave way to the utilization of the iThink software to capture the extend of the change.

2. The transformation of the causal loop models to iThink software was not straight forward. It demanded further understanding of the relationship between the variables. The relationship had to be expressed mathematically to suitably demonstrate how changes in the variables will impact on the ME. Although literature had attempted to explain the transformation process, it is not simple and easy to apply to manufacturing set ups. The key issue is to be able to extract stocks, flows, convertors and other elements of the software from the causal loop model. It demanded reformatting the causal loop model into what was termed 'structured causal loop models' before the transformation was possible. The structured causal loop models were helpful but contained some assumptions until they were utilized in the iThink software. As could be observed from the paper, the two modelling techniques were used supportively to derive the results presented. It is therefore required and essential to begin the iThink simulation model from the causal loop modelling technique since it provides a strong foundation for analysis. Also they contain minimal formal notation symbols as compared to the iThink modelling tool. However the price for this abstraction is the lack for its exactness.

3. It was observed that many factors impacted on cost and value generation. Hence the generation of a generic cost and value model will required the collection of lots of data and experiments. The system dynamics tool served as a strong modelling technique to capture most of the salient factors in the company. To the expert in modelling, it was an excellent way of illustrating the factors which could be controlled and monitored to reduce cost and improve value. An alternative way was to provide similar models for each section in the company 
and integrate them. In the top level models presented it is possible to experiment with controlled variables and examine their influence on cost and value. This is necessary for the MEs profitability and competitiveness

4. Suitable experiments could be conducted to analyse optimal performance in terms of cost and values generated by the company. The critical ordering point was established and the alternative deployment of an extra machine was experimented. It is therefore possible to generate from these system dynamics models, the outcome of possible decisions before implementation. Decisions result in actions and actions generate cost as well as values. How these are matched effectively will show how profitable the company will be. Modelling MEs by this approach has the enhanced benefit of capturing all or at least some of the factors creating dynamics in the company. When this is achieved companies are not surprised by changes and are able to predict likely consequences of events before they happen. Hence for most MEs operating in dynamic markets it is beneficial to deploy these techniques.

5. Although the authors believe that further research is needed to investigate the interplay between causal loop and iThink modelling techniques, they have observed that the causal loop modelling technique provides a suitable backbone model which usefully encode set of needed factors which can be used to facilitate the design and building of simulation models based on system dynamics principles.

To summarize, the system dynamics modelling techniques in the form of causal loop and iThink simulation models were able to capture dynamic properties impacting on cost and values for a case ME. Experiments that test the validity of models before their use were performed. The models became were used to support decision making regarding cost and value generation. The causal loop model was a suitable foundation for building the simulation model in iThink and illustrating the dynamic changes that are possible in the ME. Despite the rich knowledge provided by the causal loop models, they were not parametric and hence could not be used for quantitative analysis. They were thus supported by the iThink software to completely achieve the aims of the research. 


\subsection{Conclusions}

Aspects of dynamics impacting on cost and value in a case ME was modelled using CL and iThink modelling techniques. Through the application of these techniques:

1) key industrial dynamics were captured and their causal impact on cost and value generation identified;

2) a new approach to cost and value modelling was demonstrated. The unique advantage in this approach is that cost and values are not assumed but derived from 'causal variables';

3) an alternative understanding of value generation is presented. This is not based on internal practices but external market conditions. Internal practices influence cost and they should be controlled to match values generated.

4) problems inherent in production systems were made clear. This is because the modelling of CLs introduces cross departmental issues and therefore promote 'process integration'.

5) benefits associated with qualitative and quantitative methods were achieved. This is because CLs provided qualitative support whilst iThink gave quantitative benefits.

In addition to the above, following this modelling approach enabled interaction between key system parameters to be observed. Alternative investment plan by the company was assessed through the system dynamics model. This paper expands the manufacturing enterprise and system dynamics concept to include cost and values. Improvement in terms of cost and values made in the direction of purchasing a second equipment resulted in significant reduction in backlogs and customer lead times thereby improving company performance. The models supported the company in measuring their state of performance under increasing customer orders. Also it emphasized the need to increase sales operations to increase customer orders since below a certain ordering quantity the company will be running at a lost.

It holds that it is possible to deploy system dynamics modelling techniques in a manufacturing environment to assess the effect of various dynamics on the enterprise. 
This provides an excellent way of scientifically assessing the impact of decisions especially on key performance indicators including cost and value.

In an ongoing research work by the authors, various Enterprise Modelling (EMs) tools are being investigated to identify the possibility of integrating the strengths of EMs with SD tools especially for providing a structure around SD models and limiting the possibility of modelling several unrelated factors. 


\section{References}

Agyapong-Kodua, K. (2009). Multi-product cost and value stream modelling in support of Business Process Analysis. Wolfson School of Mechanical and Manufacturing Engineering. Loughborough, UK, Loughborough University. PhD.

Agyapong-Kodua, K., W. Bilal, et al. (2007). Process cost modelling in Manufacturing Enterprises. 4th International Conference on Digital Enterprise Technology, Bath, United Kingdom.

Ajaefobi, J. O. (2004). "Human Systems Modelling in support of Enhanced Process Realisation." PhD Thesis, Loughborough University, UK.

Akintoye, A. and E. Fitzgerald (2000). "A survey of current cost estimating practices in the UK." Construction Management Economics 18(2): 161-172.

Akkermans, H. A. (1995). "Developing a logistics strategy through participative business modelling." International Journal of Operations and Production Management 15(11): 100-112.

Askin, R. (1993). Modelling and analysis of manufacturing systems, John Wiley \& Sons.

Batur, C., A. Srinivasan, et al. (1991). "Automated rule based model generation for uncertain complex dynamic systems." Proc. of the 1991 int. symp. on intelligent control: 275-279.

Bernus, P. and L. Nemes (1996). Enterprise integration-engineering tools for designing enterprises. Australia, Chapman \& Hall.

Bicheno, J. (2000). The Lean Toolbox. Buckingham, England, PICSIE Books.

Binder, T., A. Vox, et al. (2004). Developing system dynamics models from causal loop diagrams. 22nd International Conference of the System Dynamic Society, Oxford.

Burke, F. E. (1973). Nature: 226, 246.

Burns, J. R. (2001). Simplified translation of CLDs into SFDs. Proceedings of the 19th Int. Conference of the System Dynamics Society, Atlanta, GA.

Burns, J. R. and O. Ulgen (2002). A component strategy for the formulation of system dynamics models. Proceedings of the 20th Int. Conference of the System Dynamics Society, Palermo, Italy.

Carrie, A. (1988). Simulation of Manufacturing Systems. USA, John Wiley \& Sons.

CEN/ISO (19440). "Enterprise integration - Constructs for modelling."

Chatha, K. A. (2004,). "Multi-process modelling approach to complex organisation design, PhD. Thesis." Loughborough University.

Chatha, K. A. and R. Weston (2005). "Combined Enterprise \& Simulation Modelling in support of Process Engineering." Int. J of Computer Integrated Manufacturing 18(8): 652-670.

Chatha, K. A., R. H. Weston, et al. (2003). "An approach to modelling dependencies linking engineering processes." Proceedings of Institution of Mechanical Engineers Part B: Journal of Engineering Manufacture.

Coyle, R. (1983). "The technical elements of the system dynamics approach." European Journal of Operational Research 14: 359-370.

Davis, L. E. (1982). Organization Design. New York, Wiley and Sons.

Ford, D. and J. Sterman (1998). "Dynamic modelling of product development processes." System dynamics review 14(1): 31-68. 
Forrester, J. W. (1961). Industrial Dynamics, MIT Press, Cambridge, MA.

Forrester, J. W. (1971). World dynamics. Waltham, MA, Pegasus Communications.

Forrester, J. W. (1980). "Information sources for modelling the national economy." Journal of the American Statistical Association 75(371): 555-574.

Forrester, J. W. (1992). "Policies, decisions and information sources for modelling." European Journal of Operational Research 59(1): 42-63.

Gardner, E. J. and B. Derrida (1988). "Optimal storage properties of neural network models." Journal of Physics A(21): 271-284.

Goldhar, J. D. and M. Jelinek (1983). "Plan for economies of scope." $\underline{\text { Harvard Business }}$ Review, November-December.

Homer, J. and R. Oliva (2001). "Maps and models in system dynamics: a response to Coyle." System dynamics review 17: 347-355.

Humphreys, K. (1987). Project and Cost Engineers Handbook. New York and Basel, Marrel Dekker.

ISEE (2007). isee systems,USA

Johnson, H. and R. Kaplan (1987). Relevance Lost - The Rise and Fall of Management Accounting. Boston, MA, , Harvard Business School Press.

Kosanke, K. (1996). "Process oriented presentation of modelling methodologies." Proceedings of the IFIP TC5 Working conference on models and methodologies for Enterprise Integration: 45-55.

Meadows, D. H. (1974). Dynamics of growth in a finite world. Waltham, MA, Pegasus communications.

Meadows, D. H., D. L. Meadows, et al. (1971). The limits to growth. London, WileyInterscience.

Meadows, D. H. and J. Robinson (1985). The electronic oracle: computer models and social decisions. Chichester, England, John Wiley and Sons.

Minsky, M. and S. Papert (1969). An Introduction to Computational Geometry, MIT Press.

Morecort, J. and J. Sterman (1994). Modelling for learning. Portland, Productivity press.

Mosekilde, E. (1996). Topics in nonlinear dynamics: applications to Physics, Biology and Economic systems. Singapore, World Scientific.

Pearl, J. (1985). Bayesian Networks: A Model of Self-Activated Memory for Evidential Reasoning. Proceedings of the 7th Conference of the Cognitive Science Society,, University of California, Irvine, CA.

Peterson, J. L. (1981). Petri net theory and the modelling of systems. Englewood Cliffs, NJ, Prentice, Inc.

Rahimifard, A. and R. Weston (2007). "The enhanced use of enterprise and simulation modelling techniques to support factory changeability." International journal of computer integrated manufacturing 20(4): 307-328.

Randers, J. (1980). Elements of the system dynamics method. Cambridge, MA, MIT press.

Richardson, G. (1996). Modelling for management. Aldershot, UK, Dartmouth Publishing Co.

Richardson, G. P. (1999). "Reflections for the future of system dynamics." Journal of Operational Research Society 50: 440-449. 
Rolstadås, A. A., Bjørn (editors) (2000). Enterprise Modelling, Improving global industrial competitiveness, Kluwer Academic Publishers.

Scholz-Reiter, B., M. Freitag, et al. (2004). "Modelling and control of production systems based on nonlinear dynamics theory." int. J. of Production Research.

Spooner, J. T., M. Maggiore, et al. (2002). Stable Adaptive Control and Estimation for Nonlinear Systems: Neural and Fuzzy Approximator Techniques, John Wiley and Sons, NY.

Sterman, J. (1984). "Modelling managerial behaviour: misconceptions of feedback in a dynamic decision making experiment." Management Science 35(3): 321-339.

Sterman, J. (2000). Business Dynamics: Systems thinking and modeling for a complex world, McGraw Hill.

Vernadat, F. B. (1996). Enterprise modelling and integration; Principles and Applications, Chapman \& Hall, London.

Vernadat, F. B. (2002). "UEML: towards a unified enterprise modelling language." Int. J. of Production Research 40(17): 4309-4321.

Wang, L. (1992). "Analysis and design of fuzzy systems." USC-SIPI report 206.

Weston, R. (1999). "A model-driven, component-based approach to reconfiguring manufacturing software systems." Int. J. of Operations and Production Management, Responsiveness in Manufacturing 19(8): 834-855.

Weston, R. (2005). Unified Modelling of Complex Systems - to facilitate ongoing organisation design and change Loughborough University, UK.

Weston, R. H. (1999). "A model-driven, component-based approach to reconfiguring manufacturing software systems." Int. J. of Operations and Production Management, Responsiveness in Manufacturing 19(8): 834-855.

Wiendahl, H. P. and H. Scheffczyk (1999). Simulation based analysis of complex production systems with methods of nonlinear dynamics. Institute of production systems, University of Hannover Hannover, Germany, CIRP.

Wolstenholme, E. F. (1990). System Enquiry-A system dynamics approach. Chichester, England, John Wiley and Sons.

Wolstenholme, E. F. (1999). "Qualitative verses quantitative modelling: the evolving balance." Journal of Operational Research Society 50: 422-428.

Womack, J. P. and D. T. Jones (2003). Lean thinking - Banish Waste and Create Wealth in Your Corporation. New York, Free press.

Yester, J., J. Sun, et al. (1993). "Design and automatic tuning of fuzzy logic control for an active suspension system." Proc. of the 12th IFAC World Conference.

Zhou, M. C. and K. Venkatesh (1999). Modeling, simulation and control of flexible manufacturing systems- A Petri Net Approach. Singapore, World Scientific Publishing Co. Pte. Ltd. 


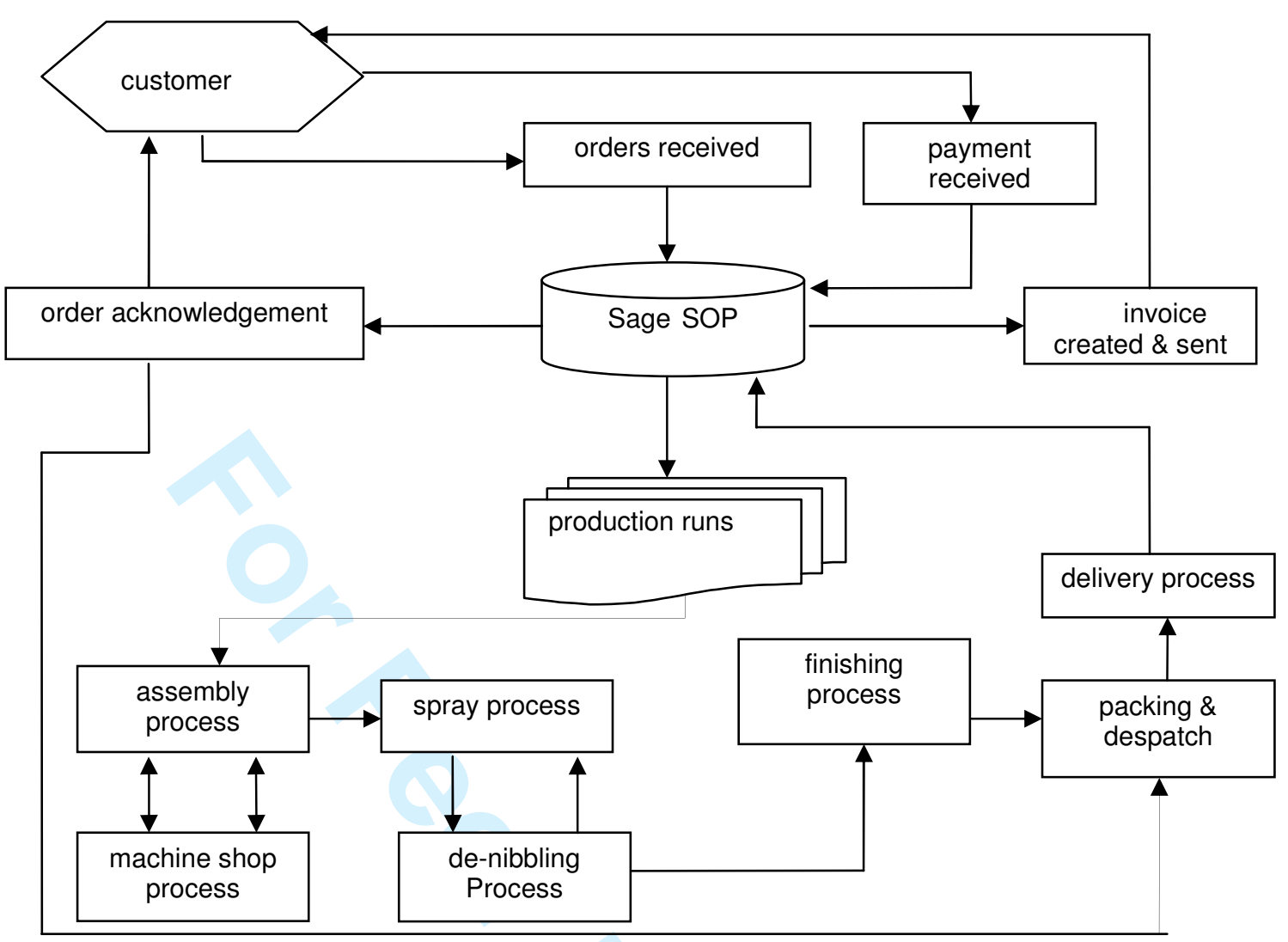

Figure 1: overview of operations in the case study company

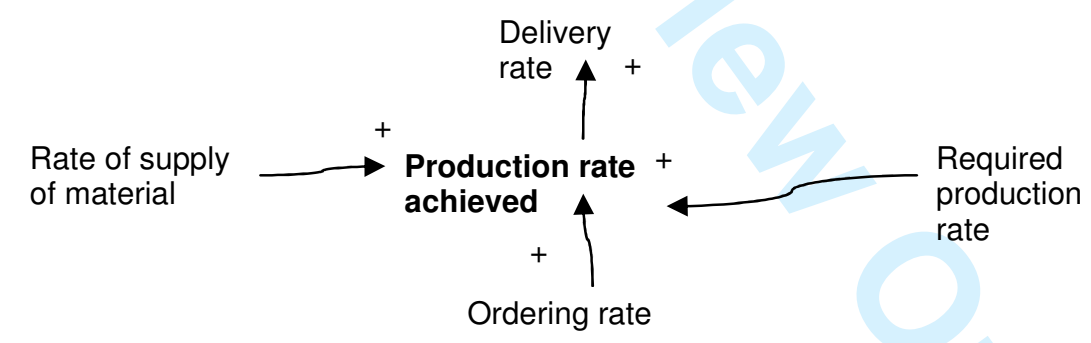

Figure 2: open causal loop illustrating factors affecting production rate achieved 


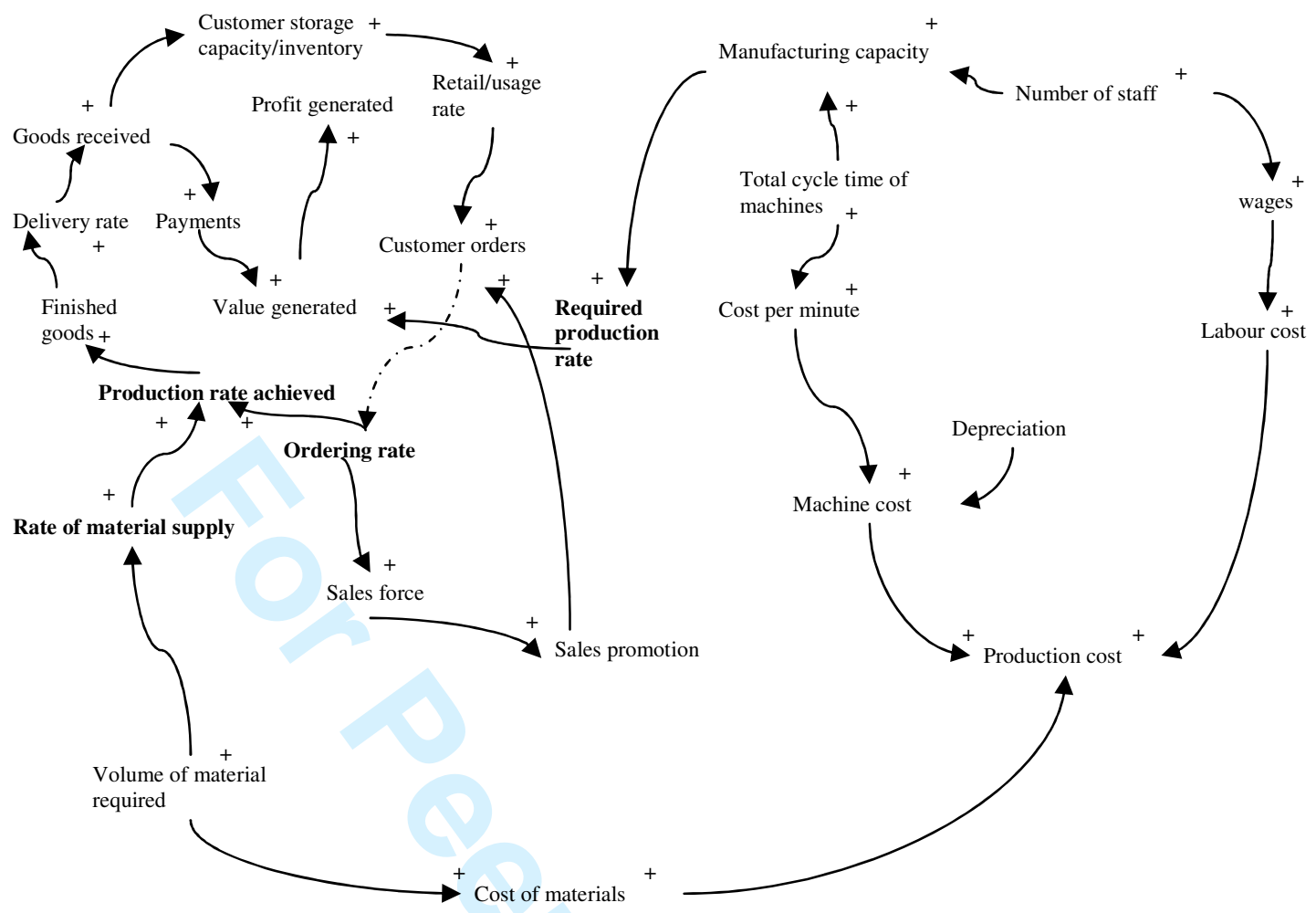

Figure 3(a): An initial causal loop model describing the impact of production activities

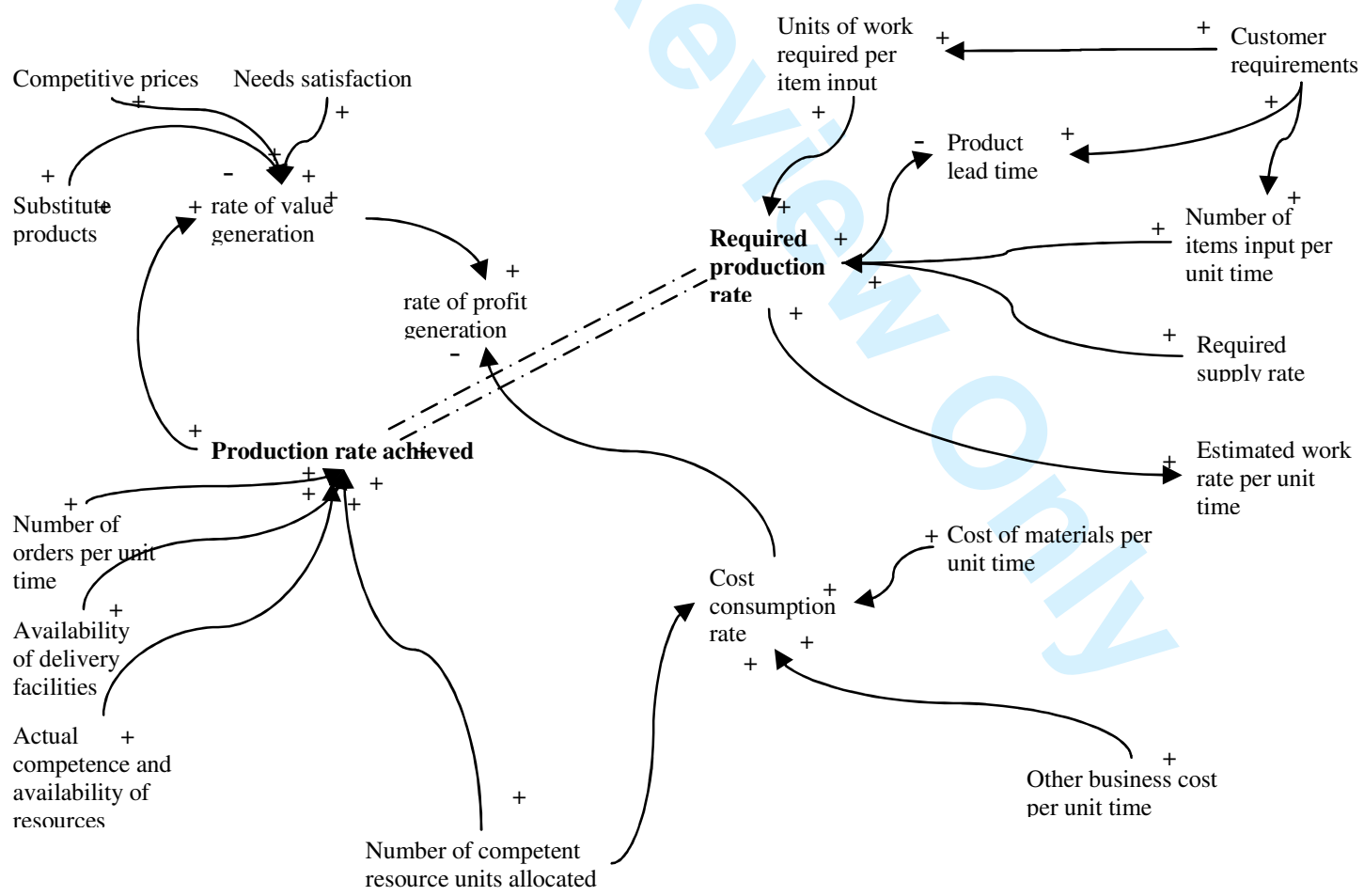

Figure 3b: Initial structured causal loop model 


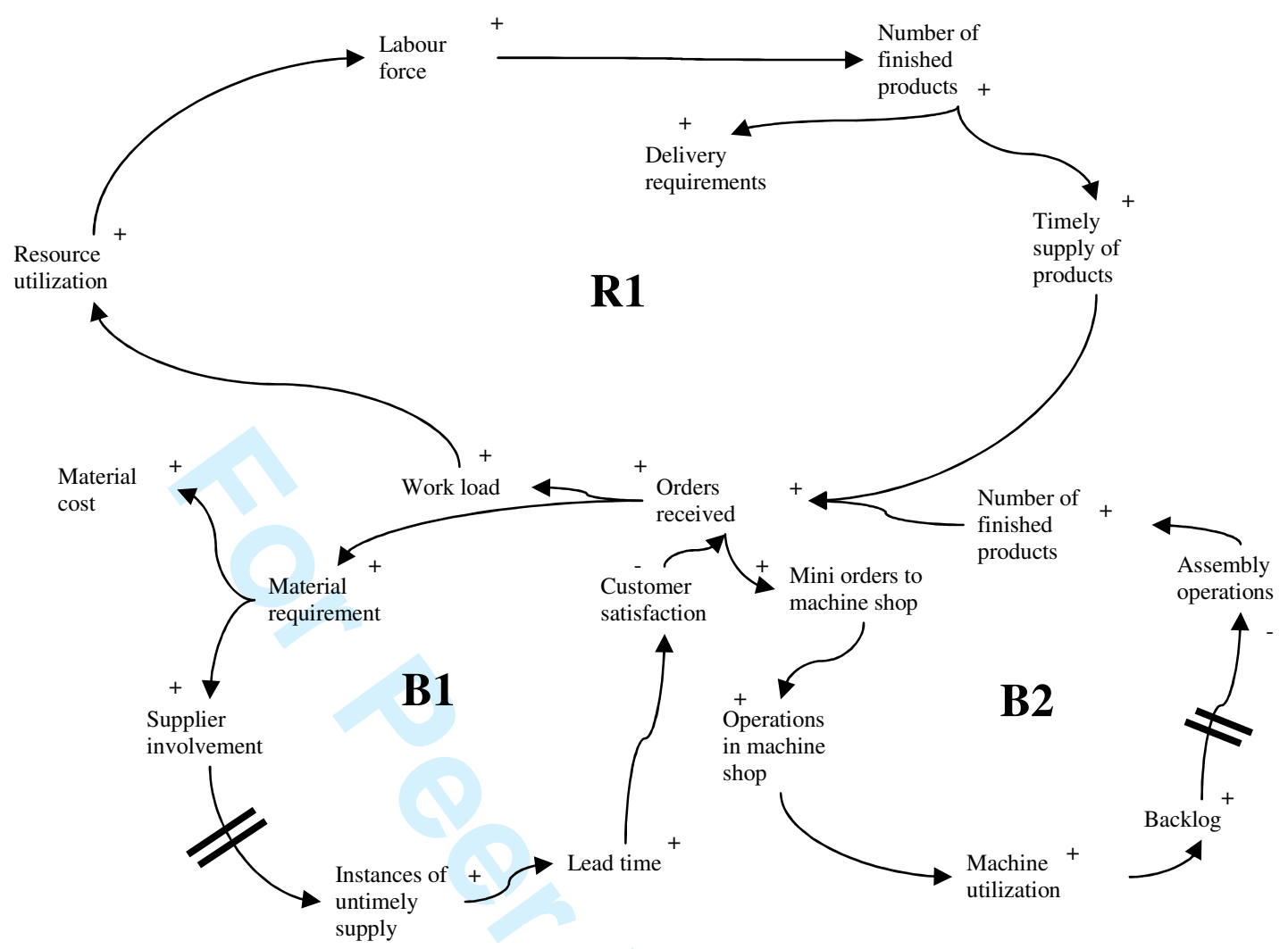

Figure 4: Balancing loops showing effect of increase in customer orders

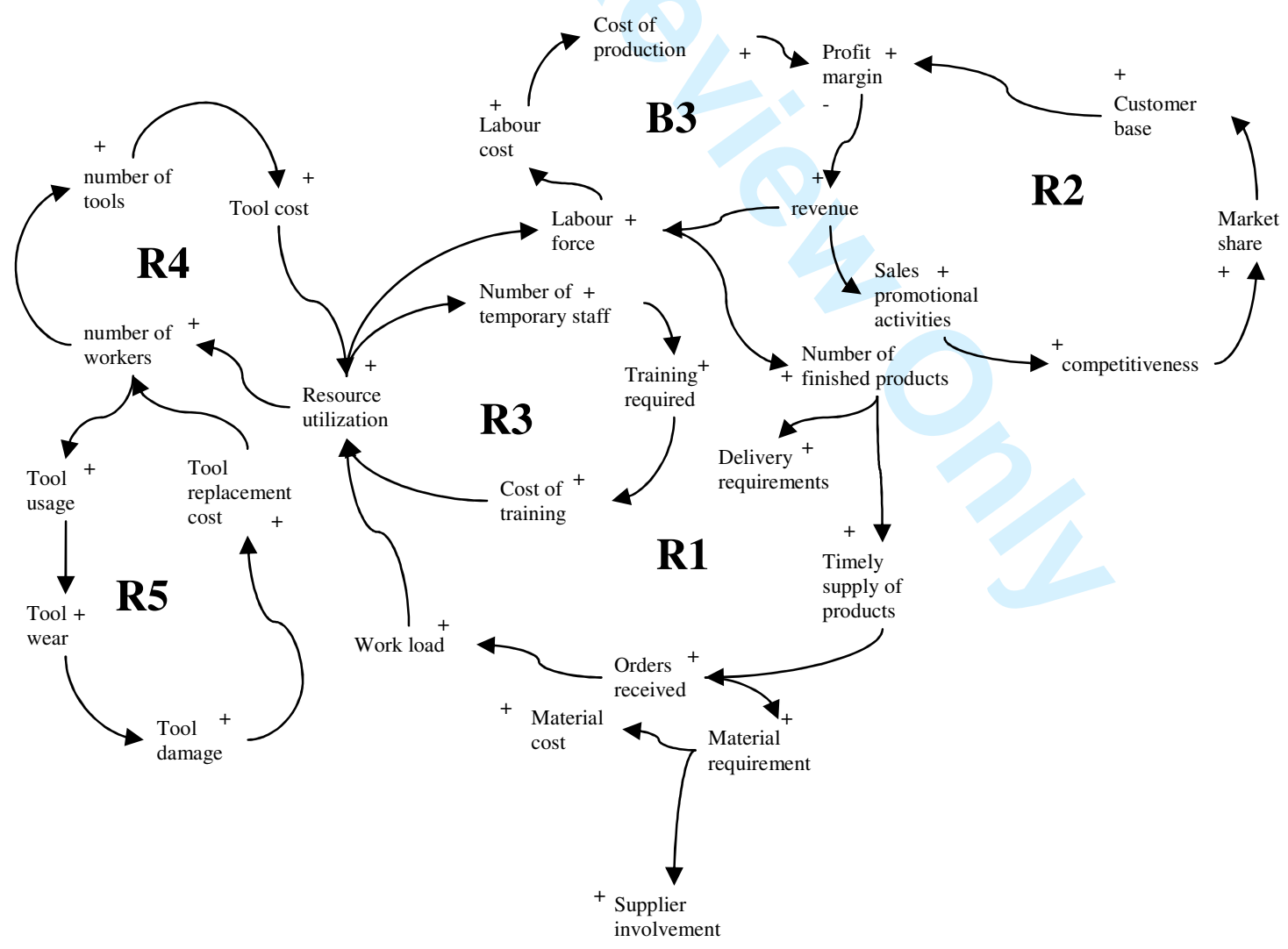

Figure 5: Loops describing impact of activities on cost 


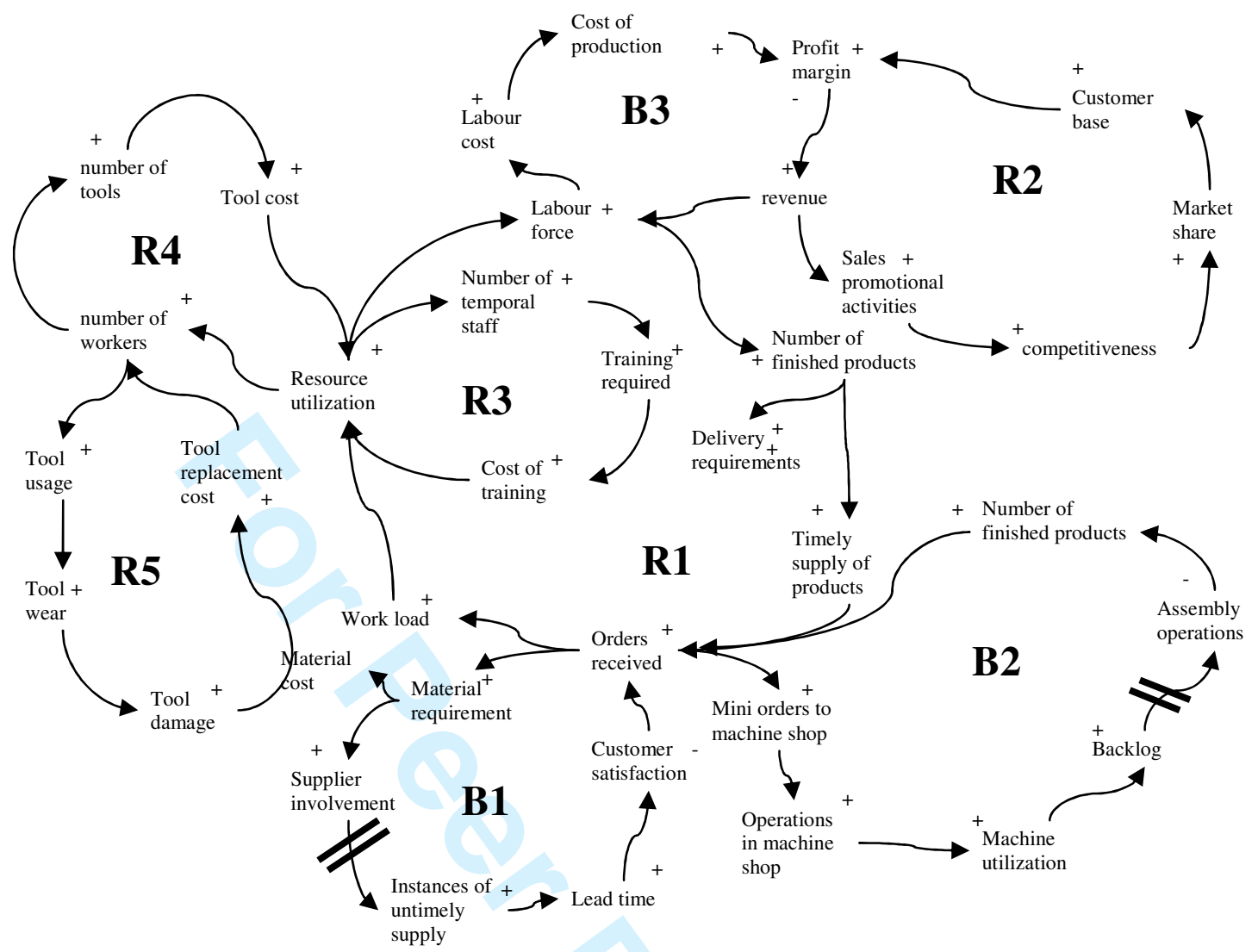

Figure 6: Influence loop 1 of case study company

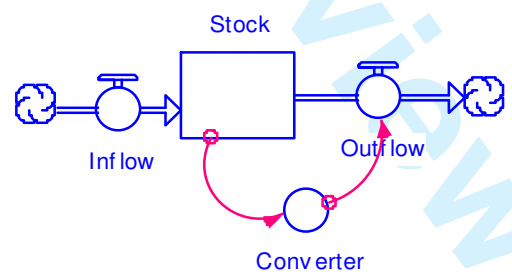

Figure 7: Elements of stock and flow models 


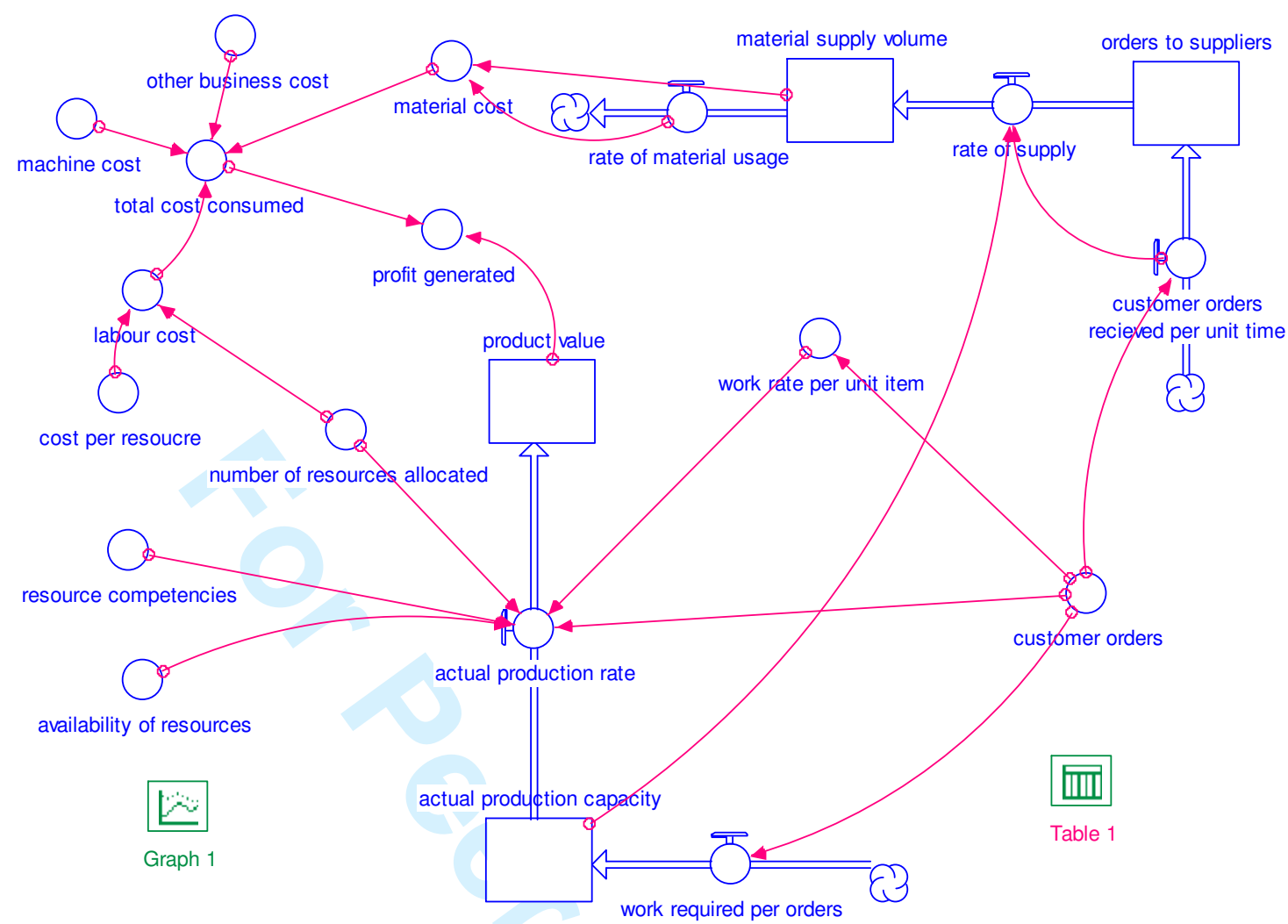

Figure 8: Portion of iThink system dynamics model

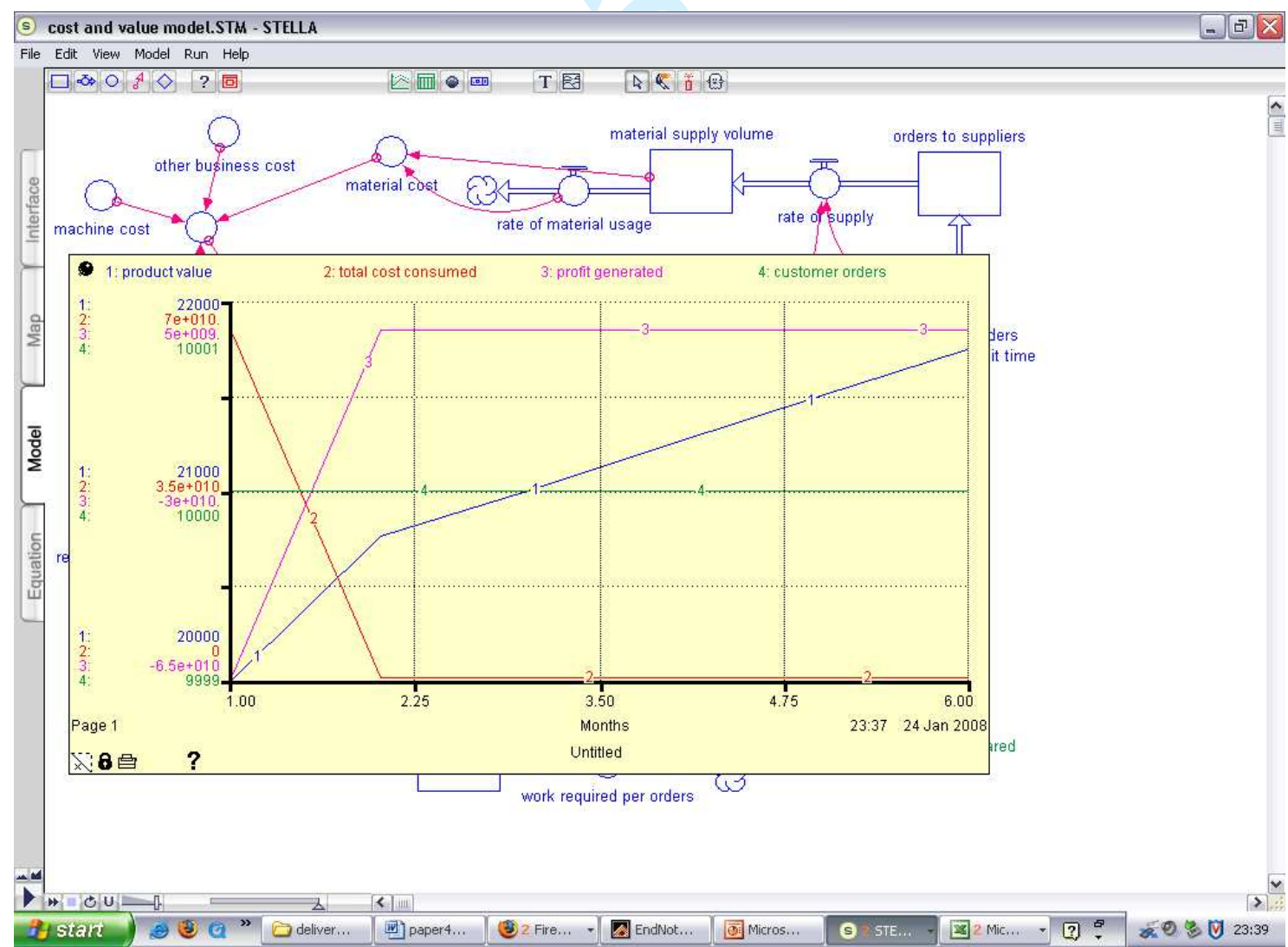

Figure 9: Sample iThink system dynamics results 


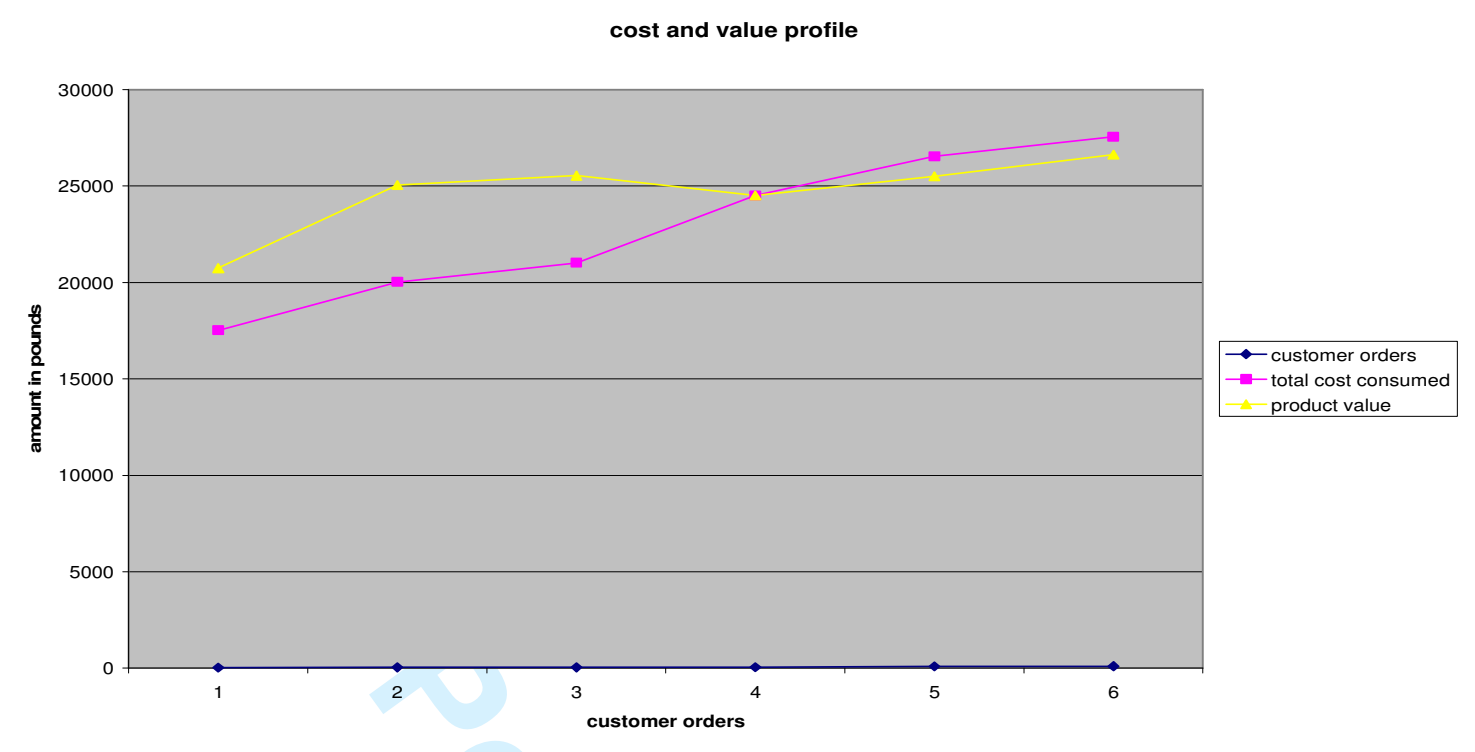

Figure 10: Graph showing the effect of increase in orders

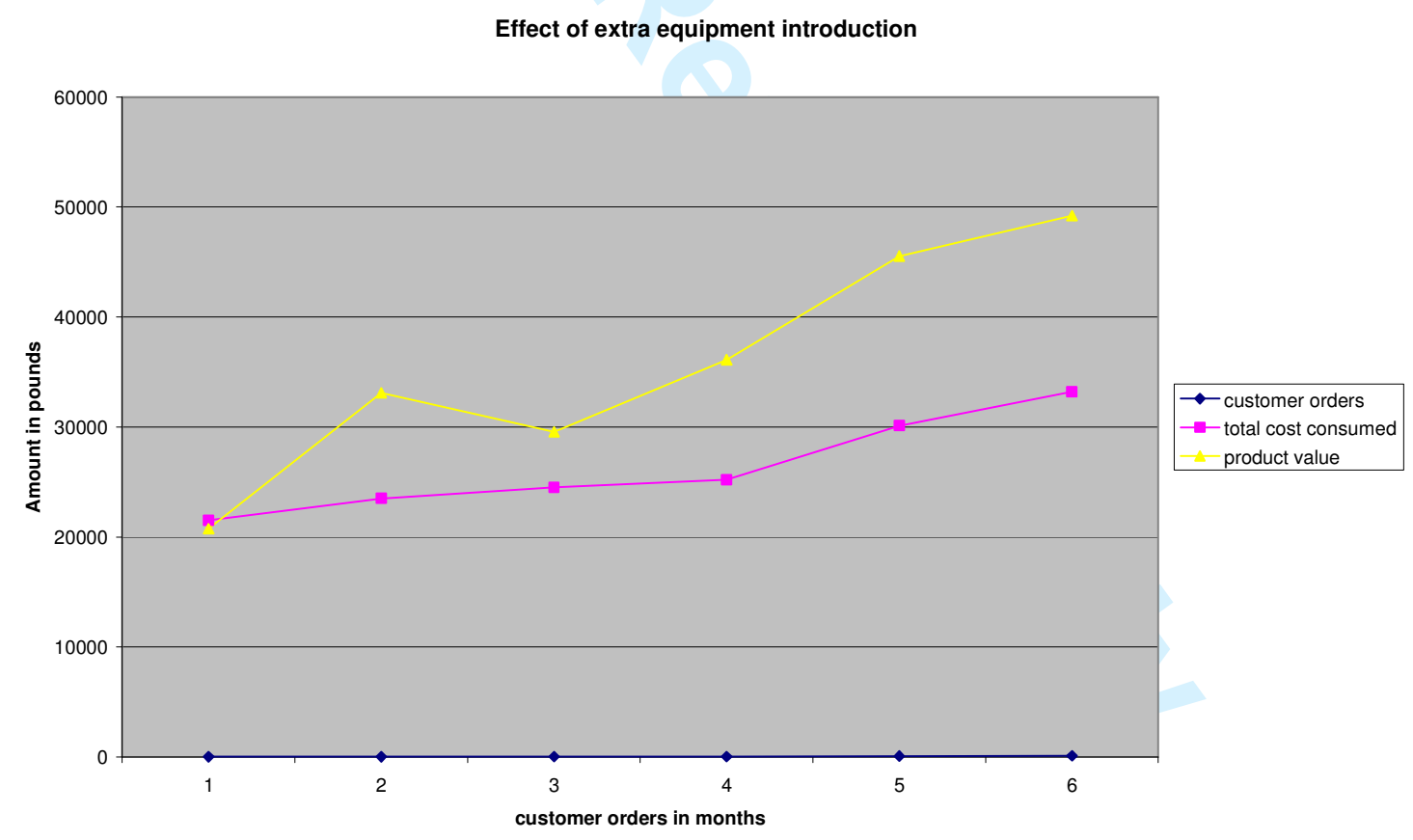

Figure 11: Graph showing the effect of introduction of new equipment 


\begin{tabular}{|c|c|c|c|c|c|}
\hline Modelling tools & $\begin{array}{l}\text { Analysis of multiproduct flows } \\
\text { and product dynamics }\end{array}$ & $\begin{array}{l}\text { Identification and } \\
\text { capturing of aspects of } \\
\text { complexities and } \\
\text { dynamics in MEs }\end{array}$ & $\begin{array}{l}\text { Reflection of causal impacts of activities } \\
\text { on financial indicators }\end{array}$ & $\begin{array}{l}\text { Ability to measure } \\
\text { process cost } \\
\text { without } \\
\text { distortions }\end{array}$ & $\begin{array}{l}\text { Availability of suitable } \\
\text { constructs for value and } \\
\text { cost modelling }\end{array}$ \\
\hline $\begin{array}{l}\text { a. Causal Loops (CL) } \\
\text { (Forrester 1961; } \\
\text { Sterman 2000; Burns } \\
\text { 2001; Burns and } \\
\text { Ulgen 2002) }\end{array}$ & $\begin{array}{l}\text { Causal loop models are not product } \\
\text { specific. They represent the causal } \\
\text { effects of activities. Specific } \\
\text { product -based causal loop models } \\
\text { can however be generated. }\end{array}$ & $\begin{array}{l}\text { The identification of } \\
\text { aspects of complexities } \\
\text { and dynamics can be } \\
\text { model through CL } \\
\text { modelling technique }\end{array}$ & $\begin{array}{l}\text { CL models can be made to depict the causal } \\
\text { impacts of activities on financial and } \\
\text { economic indicators in MEs. This depiction } \\
\text { is however qualitative and cannot accurately } \\
\text { be quantified in the CL technique. }\end{array}$ & $\begin{array}{l}\text { There are no } \\
\text { measurable } \\
\text { parameters in CL } \\
\text { modelling }\end{array}$ & $\begin{array}{l}\text { There are no established } \\
\text { constructs in CL } \\
\text { modelling. They basically } \\
\text { represent cause and } \\
\text { effects interlinked by } \\
\text { arrows and sign polarities. }\end{array}$ \\
\hline $\begin{array}{l}\text { c. Petri Net (PN) } \\
\text { (Peterson 1981; Zhou } \\
\text { and Venkatesh 1999) }\end{array}$ & $\begin{array}{l}\text { PNs can accommodate levels of } \\
\text { product complexities but will } \\
\text { require a formalized approach for } \\
\text { doing so }\end{array}$ & $\begin{array}{l}\text { PNs are suitable for } \\
\text { capturing aspects of } \\
\text { system dynamics. Process } \\
\text { models can be extracted } \\
\text { from CIMOSA or IDEF3 } \\
\text { models }\end{array}$ & $\begin{array}{l}\text { PNs are able to analyse qualitative causal } \\
\text { effects of activities of dynamic systems }\end{array}$ & $\begin{array}{l}\text { Because of the } \\
\text { mathematical } \\
\text { support in PNs, } \\
\text { they can be useful } \\
\text { in measuring costs }\end{array}$ & $\begin{array}{l}\text { There are no well } \\
\text { established constructs for } \\
\text { cost and value modelling }\end{array}$ \\
\hline $\begin{array}{l}\text { d. Bayesian networks } \\
\text { (BNs) (Pearl 2000) }\end{array}$ & $\begin{array}{l}\text { BNs is a statistical modelling tool } \\
\text { and could help classify products but } \\
\text { not model products with their } \\
\text { process. It is not a process } \\
\text { modelling tool }\end{array}$ & $\begin{array}{l}\text { BNs are capable of } \\
\text { representing aspects of } \\
\text { dynamics and } \\
\text { complexities in MEs in } \\
\text { the form of variables and } \\
\text { their probabilistic } \\
\text { independencies }\end{array}$ & $\begin{array}{l}\text { Causal relations can be captured and } \\
\text { represented as conditional dependences and } \\
\text { used for onward analysis }\end{array}$ & $\begin{array}{l}\text { Efficient } \\
\text { algorithms exist } \\
\text { which can be } \\
\text { designed to } \\
\text { identify process } \\
\text { costs without } \\
\text { distortions }\end{array}$ & $\begin{array}{l}\text { There are no existing } \\
\text { constructs for cost and } \\
\text { value modelling }\end{array}$ \\
\hline $\begin{array}{l}\text { e. Fuzzy logic (FL) } \\
\text { (Batur, Srinivasan et } \\
\text { al. 1991) (Wang } \\
\text { 1992) }\end{array}$ & $\begin{array}{l}\text { FL feeds on the fuzzy set theory to } \\
\text { support reasoning but it does not } \\
\text { explicitly model processes. }\end{array}$ & $\begin{array}{l}\text { Complexities can be } \\
\text { expressed but in a } \\
\text { statistical manner }\end{array}$ & $\begin{array}{l}\text { Causal relations could be depicted but } \\
\text { limited to variables and not processes }\end{array}$ & $\begin{array}{l}\text { Process cost can be } \\
\text { estimated with FL }\end{array}$ & $\begin{array}{l}\text { No value and cost } \\
\text { constructs exist }\end{array}$ \\
\hline $\begin{array}{l}\text { f. Neural networks } \\
\text { (NNs) (Minsky and } \\
\text { Papert 1969; } \\
\text { Gardner and Derrida } \\
\text { 1988; Spooner, } \\
\text { Maggiore et al. 2002) }\end{array}$ & $\begin{array}{l}\text { Factors influencing multiproduct } \\
\text { flow can be developed and } \\
\text { modelled through the application of } \\
\text { NNs but not as a process. For } \\
\text { example, NNs can be used to group } \\
\text { products into their respective } \\
\text { classes based on a mathematical or } \\
\text { relational algorithms. it cannot } \\
\text { match graphically products to their } \\
\text { processes }\end{array}$ & $\begin{array}{l}\text { The application of NNs in } \\
\text { real life is suitable for } \\
\text { modelling complexities } \\
\text { especially the complexity } \\
\text { of data and not ME design }\end{array}$ & $\begin{array}{l}\text { It is capable of reflecting causal impacts } \\
\text { through the expression of algorithms }\end{array}$ & $\begin{array}{l}\text { NNs possess the } \\
\text { ability to measure } \\
\text { process cost } \\
\text { through the } \\
\text { formulation of } \\
\text { algorithms }\end{array}$ & No constructs really exist \\
\hline
\end{tabular}

Table 1: Review of system dynamics modelling tools 


\begin{tabular}{|c|c|c|c|}
\hline $\begin{array}{l}\text { total cost consumed } \\
(£)\end{array}$ & product value (£) & profit generated (£) & $\begin{array}{c}\text { customer } \\
\text { orders }\end{array}$ \\
\hline 17511.4 & 20750 & 3238.64 & 20 \\
\hline 17511.4 & 20750 & 3238.64 & 20 \\
\hline 17511.4 & 21000 & 3488.64 & 20 \\
\hline 17511.4 & 21250 & 3738.64 & 20 \\
\hline 17511.4 & 21500 & 3988.64 & 20 \\
\hline 17511.4 & 21750 & 4238.64 & 20 \\
\hline
\end{tabular}

Table 2: Sample simulation results 